\title{
Palm-sized device for point-of-care Ebola detection
}

Christian D. Ahrberg, ${ }^{1}$ Andreas Manz, ${ }^{1}$ and Pavel Neuzil ${ }^{2,3 *}$

${ }^{1}$ KIST Europe, Campus E7.1, 66123 Saarbrücken

${ }^{2}$ Northwestern Polytechnical University (NPU), School of Mechanical Engineering, Department of Microsystem Engineering, 127 West Youyi Road, Xi'an, Shaanxi, 710072, P. R. China

${ }^{3}$ Brno University of Technology, Antonínská 548/1, Brno 601 90, Czech Republic

*Corresponding author: pavel.neuzil@gmail.com

Supplementary information:

S1: Repetition of real time PCR

S2: Repetition of melting curve analysis

S3: Repetition of negative derivative of melting curve analysis 
S1. Repetitions $(n=3)$ of the amplification curves recorded using the handheld device. Each sample was tested three times on different positions of the handheld device in three separate runs of the device. All samples contained the same templates, such as RNA of Ebola virus as well as the RNA of GAPDH gene. They only differ in used oligonucleotides. The data were then normalized by subtracting the baseline and dividing the residuum by its maximum value. The deviation in threshold cycles are probably caused by different droplet positioning and the small heater as well as by pipetting error.

(A) Sample containing two sets of primers specific to both CDNA of GAPDH gene as well as to the cDNA of Ebola virus RNA. This sample was used as positive control. Value of threshold cycle $\left(C_{T}\right)$ was $(21.49 \pm 0.40)$ (mean \pm standard deviation).

(B) Sample containing primers specific only to cDNA of GAPDH gene. Value of its $C_{T}$ was $(28.06 \pm 0.17)$ (mean \pm standard deviation).

(C) Sample containing primers specific only to cDNA of Ebola virus RNA. Value of its $C_{T}$ was $(27.45 \pm$ $0.52)$ (mean \pm standard deviation).
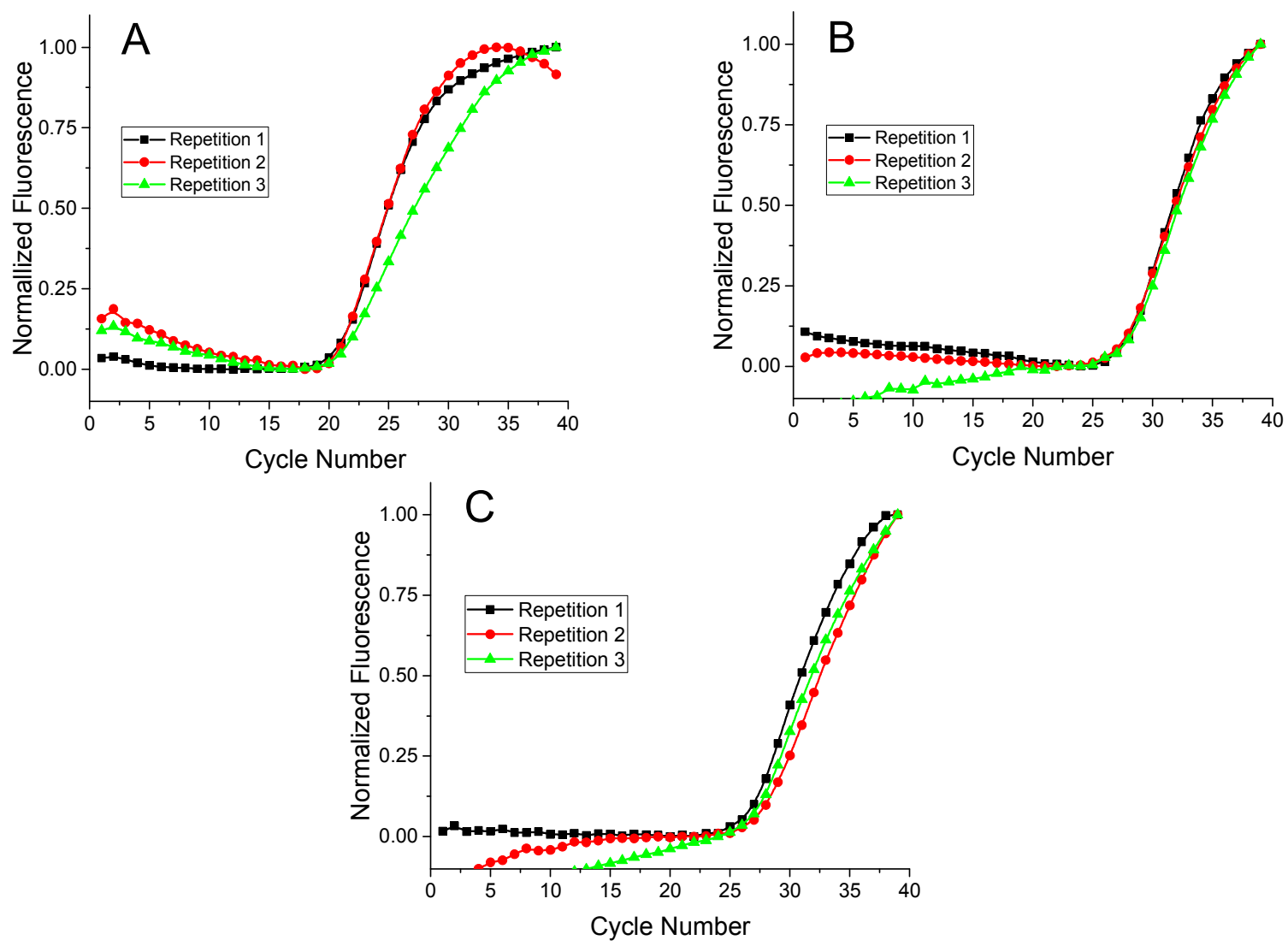
S2. Repetitions ( $n=3$ ) of melting curve analysis (MCA) performed by the handheld device after cDNA amplification by PCR. All samples contained the same templates, such as RNA of Ebola virus as well as the RNA of GAPDH gene. They only differ in used oligonucleotides. Deviations between melting temperatures between runs are most likely due to different positioning of droplets and pipetting error. Processed data with standard deviations are shown in Fig. S3.

(A) Sample containing two sets of primers specific to both CDNA of GAPDH gene as well as to the cDNA of Ebola virus RNA. This sample was used as positive control.

(B) Sample containing primers specific only to cDNA of GAPDH gene.

(C) Sample containing primers specific only to cDNA of Ebola virus RNA.
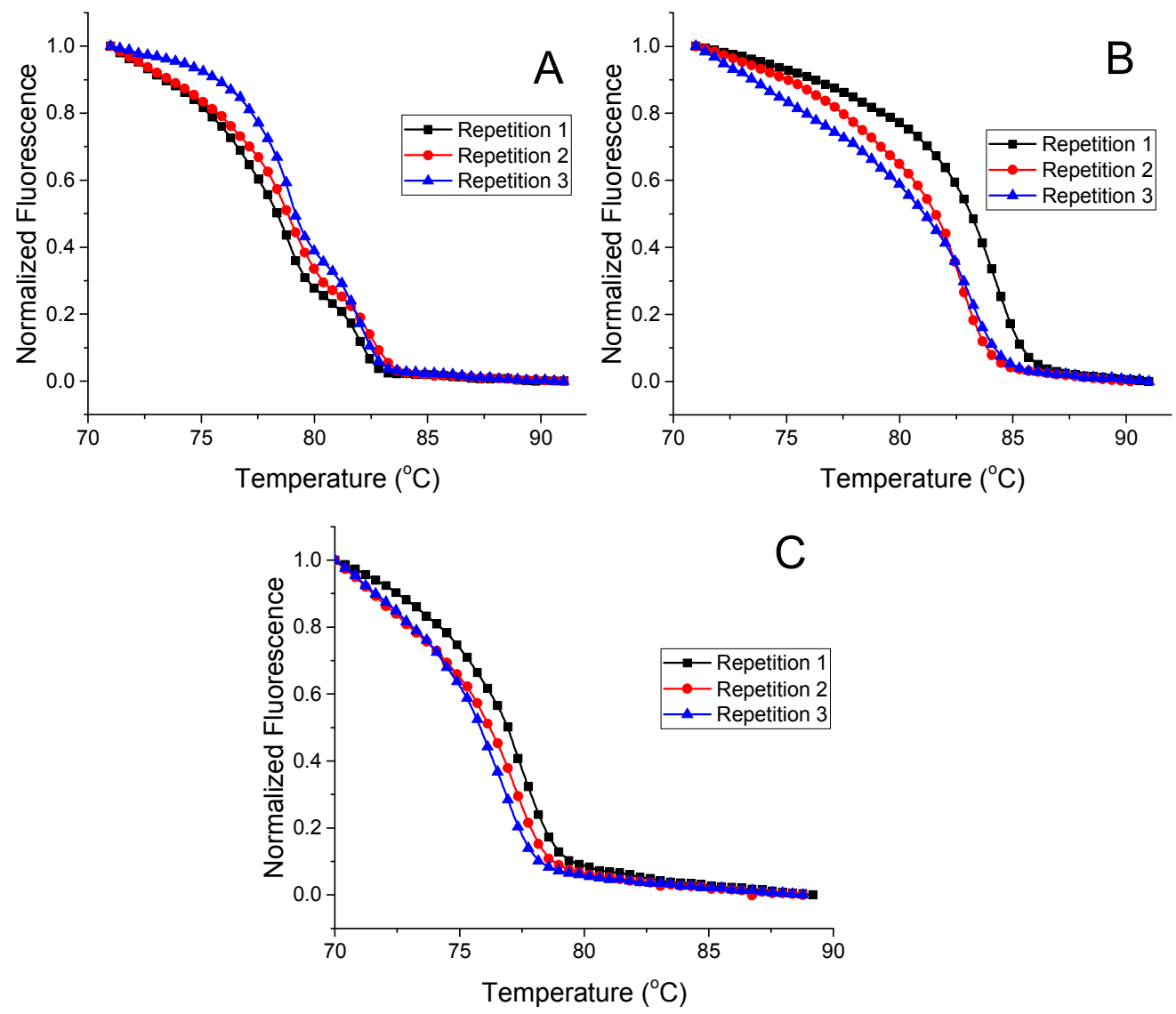
S3. MCA performed by negative derivatives of melting curved with respect to temperature from Figure S2. All samples contained the same templates, such as RNA of Ebola virus as well as the RNA of GAPDH gene. They only differ in used oligonucleotides.

(A) Sample containing two sets of primers specific to both CDNA of GAPDH gene as well as to the cDNA of Ebola virus RNA. Two peaks at the MCA with melting temperature $T_{M}$ value of $(78.82 \pm 0.13)$ ${ }^{\circ} \mathrm{C}$ and $(82.15 \pm 0.26){ }^{\circ} \mathrm{C}$, both (mean \pm standard deviation) confirms successful amplification of both amplicons. This sample was used as positive control.

(B) Sample containing primers specific only to cDNA of GAPDH gene. The single peak at MCA with melting temperature value of $(83.37 \pm 0.75)^{\circ} \mathrm{C}$ (mean \pm standard deviation) confirms that RT-PCR resulted only in one amplicon with correct value of melting temperature.

(C) Sample containing primers specific only to CDNA of Ebola virus RNA. The single peak at MCA with melting temperature value of $(77.12 \pm 0.41)^{\circ} \mathrm{C}$ (mean \pm standard deviation) confirms that RT-PCR resulted only in one amplicon with correct value of melting temperature.
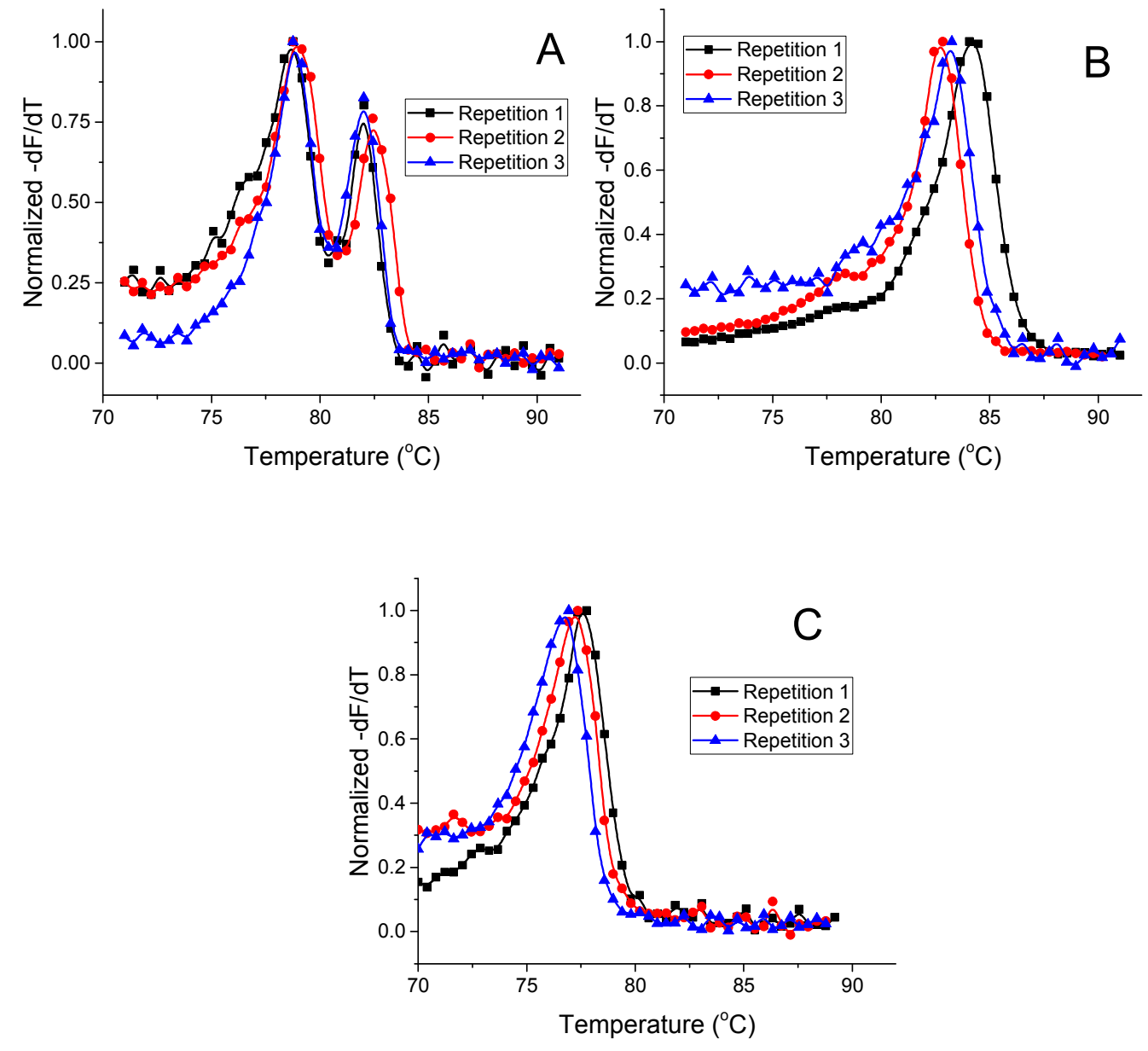